International Journal of Life Sciences
Available online at http://sciencescholar.us/journal/index.php/ijls
Vol. 2 No. 2, August 2018, pages: $64 \sim 72$
e-ISSN: 2550-6986, p-ISSN: 2550-6994
https://doi.org/10.29332/ijls.v2n2.176

\title{
Mercury: Risks and Handling as Hazardous Waste
}

\author{
(1) corssiank \\ Mariano Cesar Gurris Suarez a, Virginia Gonzalez Gonzalez ${ }^{\text {b }}$ \\ Article history: Received 10 April 2017, Accepted in revised form 20 May 2018, Approved 10 August 2018,
} Available online 28 August 2018

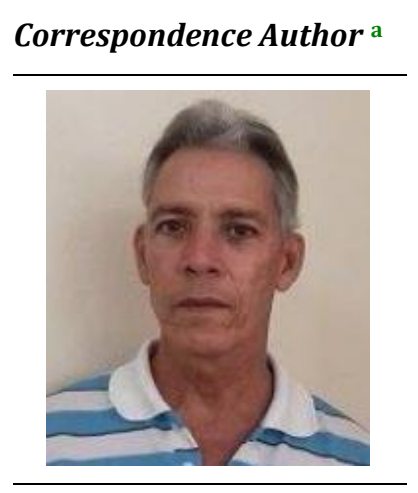

Keywords

Environmental management; Hazardous waste; Management plan; Mercury; Soils characteristics;

\begin{abstract}
The handling of some chemical substances, as is the case of Mercury used in the determination of the contraction characteristics of soils, becomes dangerous waste at the end of the test process, which requires an adequate management having as a reference the established measures in the legislation and complying with the legal and applicable requirements in this matter. In the present work the characteristics of the mercury, the measures for its use, transportation, and/or storage, as well as the risks to the occupationally exposed workers, are related in the Laboratories of the Applied Research Company. The objective of this research is to raise the culture in the procedures for the handling of chemical substances and hazardous waste, in the use and care of the means of individual protection, as well as compliance with everything established in the procedures for the realization of activities related to the use of mercury to form an environmental awareness focused on achieving an excellent quality of life in the workplace and contribute to the protection of the environment.
\end{abstract}

e-ISSN: 2550-6986, p-ISSN: 2550-6994 C Copyright 2018. The Author. Published by ScienceScholar in Universidad Técnica de Manabí. This is an open-access article under the CC-BY-SA license (https://creativecommons.org/licenses/by/4.0/) All rights reserved.

\section{Contents}

Abstract

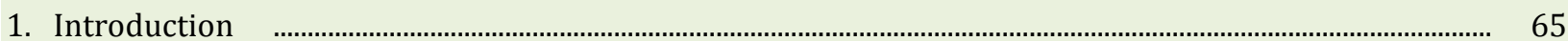

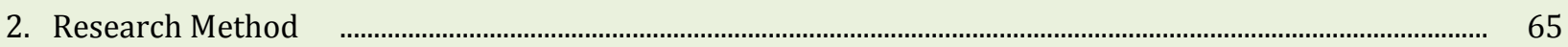

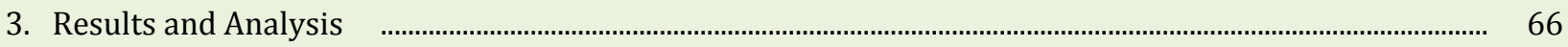

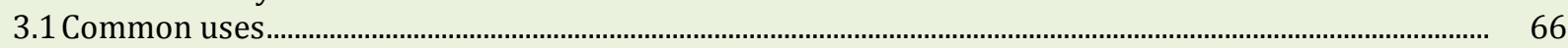

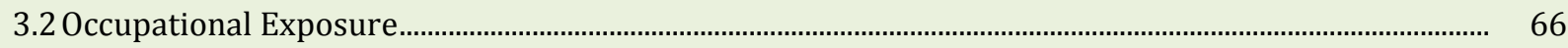

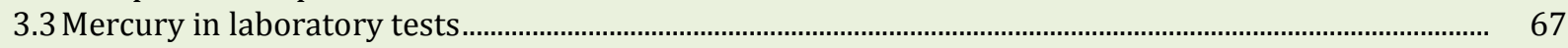

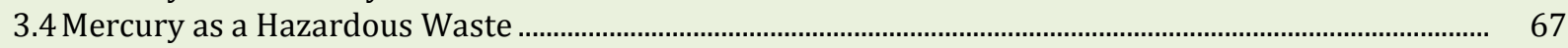

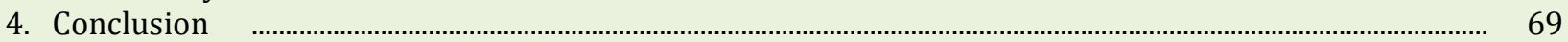

a Department of Engineering and UIC Project, Santiago de Cuba, Cuba

b Department of Engineering and UIC Project, Santiago de Cuba, Cuba 


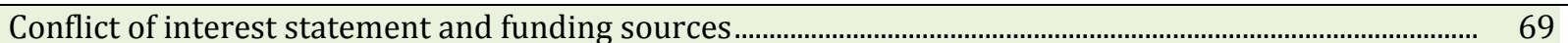

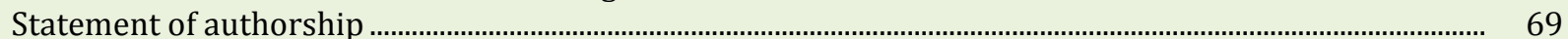

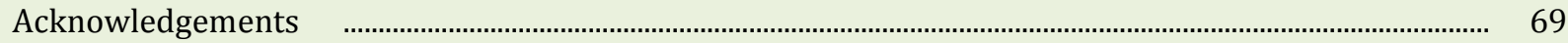

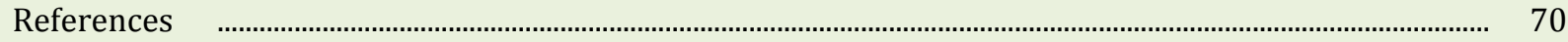

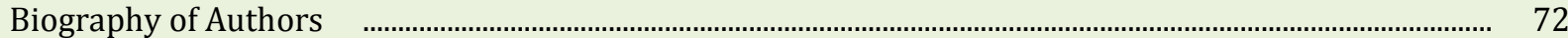

\section{Introduction}

It is the duty of all to have knowledge and be updated in the scenarios that generate risks for the life of man and which in turn have an impact on the quality of the work environment when exposed to chemical elements, which in one way or another are inhaled and in Many of the cases have contact with the skin and that obviously cause collateral damage to the body.

The Construction Research Unit (IUC), prepares and imparts training to those involved, for the sake of their health, it would not be enough if there was no sense of individual responsibility to the risk they are subject to if they do not adequately use the means of security and protection.

In this sense, the WHO World Health Organization formulated the following definition:

"La Medicine of the Work aims to promote and maintain the highest degree of physical, mental and social well-being of workers of all professions, prevent any possible damage caused to their health by working conditions, protect them in their jobs against risk resulting from the presence of harmful agents, placing and keeping the worker in a job convenient to their physiological and psychological aptitudes, adapting work to man and each man to his work.

Based on the fact that the health of workers and the problems of occupational hygiene became the foundations of Cuban state policy, in the sphere of public health and occupational health we explain the definition and characteristics of mercury as a substance. Mercury, a heavy metal widely used by man, is very toxic; it causes damage to the central nervous system, behavioral disturbances, and kidney damage. It accumulates in all living beings and is not essential for any biological process [1] as well as the concept of hazardous waste.

Mercury or quicksilver is a chemical element, with an atomic number of 80. Its symbol is $\mathrm{Hg}$. Its name is given in honor of the God Mercury since it was the messenger of the Gods, due to its great mobility [2]. The mercury or quicksilver and its main mineral, cinnabar, were known by different cultures since ancient times, attracted by their properties and applications in different fields. The Greeks and Romans used cinnabar as paint (vermillion) [3]. Some of its most renowned doctors, such as Hippocrates, used it as an ointment because it was not considered toxic by the skin. It is even documented that Plinio warned workers in the cinnabar mines that they should protect their faces with masks made of thin skins to avoid inhaling the mineral dust. It is just at this time when mercury becomes very important as a metal in the civilized world [4]. It is known, in addition to its toxicity, the medicinal property as a disinfectant and healing of burns.

\section{Research Method}

A study of the characteristics of mercury as a heavy, silver metal was made from a bibliographic study, at room temperature it is an odorless liquid; it is allied with some metals such as gold, silver, producing amalgams; it is not a good ally with iron; It is insoluble in water and soluble in nitric acid; to 40.c produces toxic and corrosive vapors heavier than air; It is incompatible with nitric acid, acetylene, ammonia, chlorine and other metals.

The conditions caused were evaluated and the parameters of being considered as hazardous waste were taken into account when being in the substances or article that are in the list of the wastes and that due to their physical, biological or chemical characteristics, could represent a danger for to the environment and human health. 


\section{Results and Analysis}

Requirements for Transportation: It must be transported in a liquid state; The containers must be hermetically sealed; These should be made of steel, stainless steel, iron, plastic, glass or porcelain; Containers should not be lead, aluminum, copper, tin or zinc; Store in cold, dry and well-ventilated areas; Remove it from solar radiation and sources of heat or ignition; It must be kept away from concentrated nitric acid, acetylene and chlorine.

Mercury is a liquid radioactive isotope, easy to penetrate into the human body via inhalation and contact, belongs to the type of environmental source so you must take extreme care in handling [5].

identification or Labeling.

In accordance with the European Union Legislation, for a correct identification of this toxic product, the following phrases must be incorporated into the labels: R: R 23 (Toxic by inhalation); R 33 (Danger due to cumulative effects) The phrases must also be incorporated:

S: S $1 / 2$ (Keep locked up and out of the reach of children) and S 45 (In case of accident or if you feel unwell, seek medical advice immediately, show the label where possible).

\subsection{Common uses}

\section{Mercury can be found in fluorescent tubes [6], thermometers, batteries and dental amalgams.}

Effects on the organism: High levels of metallic or organic Mercury can permanently damage the brain, the kidneys, and the developing fetus; can cause acute and chronic poisoning; it is harmful by inhalation, ingestion, and contact; irritant product for the skin, eyes and respiratory tract; in the short term, emanations of high levels of mercury vapors, damage the lungs, cause nausea, vomiting, diarrhea, increased blood pressure, heart rhythm and skin rashes; permanent exposure, develops a fine tremor and can escalate to violent muscle spasms; the tremor begins in the hands and then extends to the eyelids, lips, and tongue; in the long term, it has been associated with symptoms such as fatigue, irritability, loss of memory, lived dreams and depression; profound effects of the central nervous system include psychotic reactions, producing delusions, hallucinations and suicidal tendencies; It results in wide-ranging functional disorders, including irritability, nervousness, excessive shyness and insomnia [9].

Damage to the fetus

The harmful effects of Mercury can be transmitted from the mother to the fetus and includes brain damage, mental retardation, lack of coordination, blindness, seizures, and inability to speak, problems in the nervous system, digestive and kidney damage [10].

Children who have contact with mercury of any kind develop acrodynia ("pink disease"): flushing, pruritus, edema, tachycardia, hypertension, salivation or excessive sweating, irritability, weakness, morbilliform erythema, desquamation of the palms of the hands and the soles of the feet.

\subsection{Occupational Exposure}

The WHO World Health Organization, the Occupational Health and Safety Assessment Series OSHA and the National Institute for Safety and the National Institute for Occupational Safety and Health (NIOSH) establish that all Mercury must be treated as a work hazard and have established specific limits of occupational exposure [11].

The emissions to the Environment and the elimination of Mercury in Cuba are regulated considering the risks to which those who operate this product are exposed, the Evaluation of 3 is taken, qualified as High Risk for health, as established in the Procedure of Identification and Evaluation of Environmental Aspects RGA 01A.

Within the Occupational Health Program, among the actions that are developed for the control of all workers exposed to toxic substances such as Lead, Silica, Mercury, and Pesticides. These exposed workers are 
examined for urine, X-rays of the chest, mercury in the urine and blood cholinesterase periodically in the specialized laboratories of the Public Health System [12], [16].

3.3 Mercury in laboratory tests

In the particular case of the Materials Laboratory of the UIC Santiago de Cuba, mercury is used to perform the physical test on samples tested in their liquid form to determine the limit of contraction where each soil sample used weighs 85 to $95 \mathrm{~g}$ and then it becomes a dangerous waste.

Figure 1 shows images of the laboratory tools used in the test to determine the limit of soil contraction [13].
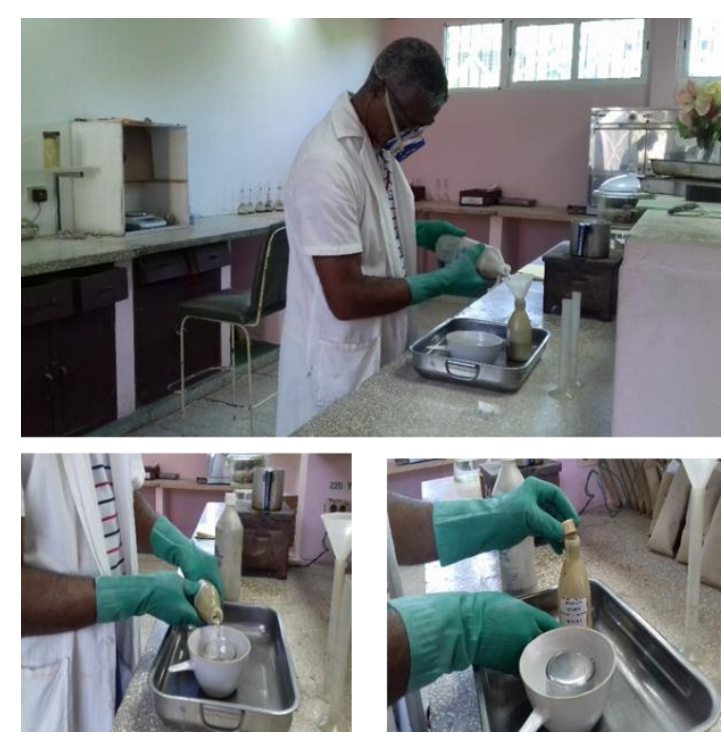

Figure 1. Utensils used in the test for the limit determination of soil contraction

\subsection{Mercury as a Hazardous Waste}

Based on the provisions of Article 155 of the Environmental Law [14] and the Basel Convention where Cuba is a signatory, measures are adopted for the Management of Hazardous Waste in accordance with the provisions of the Management Regulations. The objective of the latter is to establish the provisions that contribute to ensuring the integral management of hazardous waste in the country, by preventing their generation at the source and safe handling throughout of its life cycle, in order to minimize risks to human health and the environment, including those related to transboundary movements.

The Construction Research Unit of Santiago de Cuba UIC has identified the hazardous waste generated in each of the processes through the Hazardous Waste Management Plan, where each of the measures to be taken to minimize the impacts is well defined. Derivatives through appropriate practices that includes the training of personnel on issues associated with their management [15].

According to Resolution 136/09, the General Classification of Hazardous Waste is established, where it appears that Mercury is a hazardous waste that is obtained as a result of laboratory analysis in determining the contraction limit in soil samples. This analysis aims to determine the percentage of moisture with which the soil contracts. For this analysis, the provisions of the Geotechnical Standard are followed. Determination of the liquid limit, plastic limit, and plasticity index of the soils once the analysis is done, the small samples are stored in an area destined for these purposes until their final destination is defined by competent authorities, always with their proper signage Y29 as set forth in Resolution 136/09 [12], as shown in Figure 2 

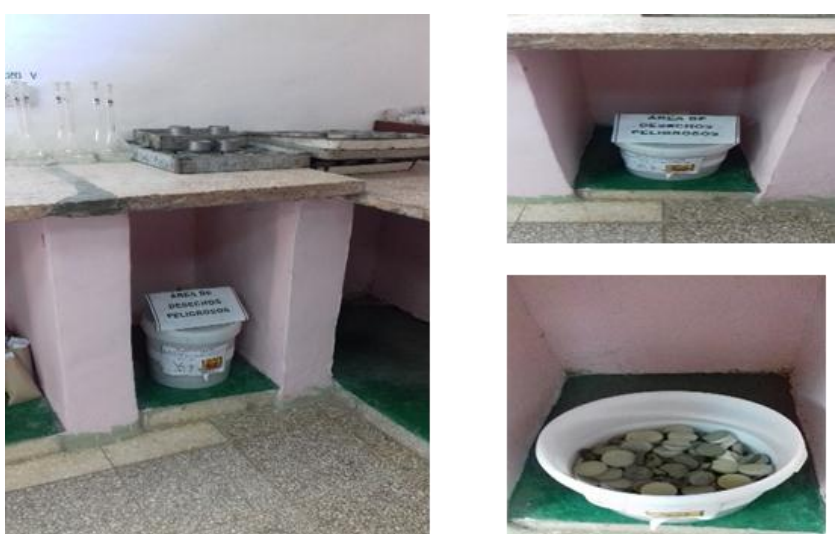

Figure 2. Storage of soil contaminated with mercury

Mercury as a hazardous waste is also present in fluorescent luminaires that are removed once their useful life is over and are temporarily stored in a previously established area with their respective Y29 signaling, foreseeing that they should not be broken to prevent the mercury leaking into the medium, figure 3 shows the storage of the luminaires.

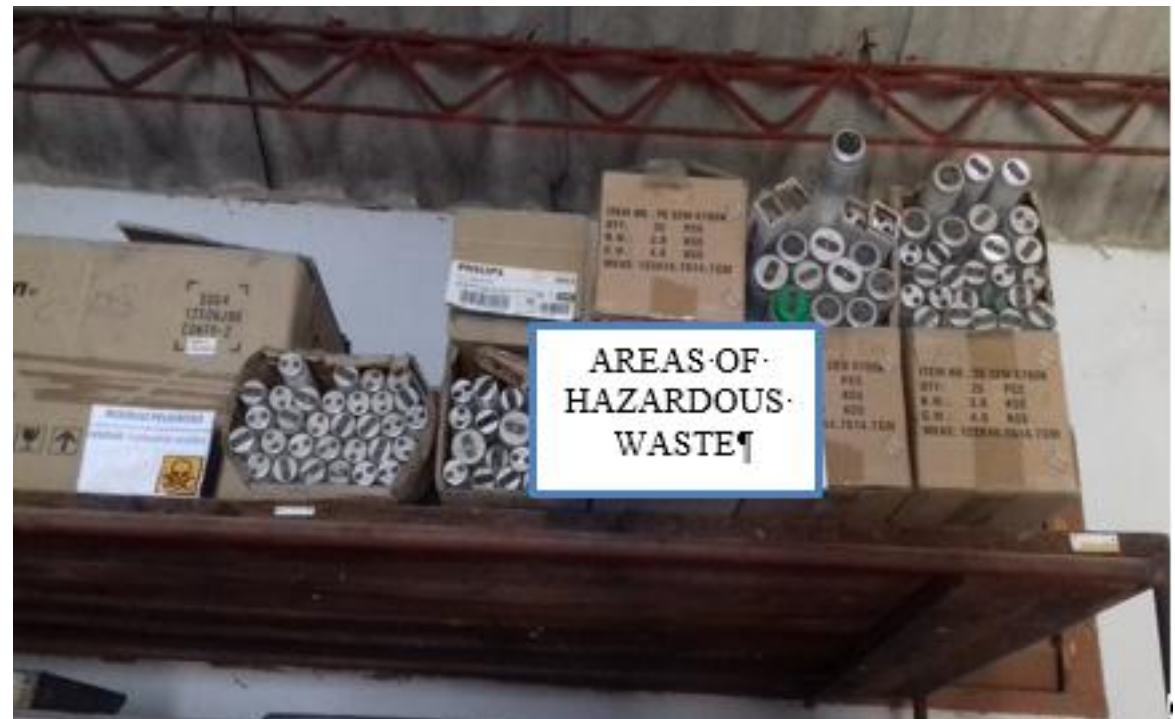

Figure 3. Area destined for the storage of the luminaries (UIC Santiago de Cuba)

At present, this type of hazardous waste is only collected by the state sector where the daily stock is more considerable, despite the fact that the mercury content in each luminaire is so small approximately $0.03 \mathrm{mg}$ per luminaire, even the regulatory body. In this case, the CITMA has not defined the final destination, although it is known that the possibility of being stored as a final destination in the old Nuclear Power Plant (CEN) of Juragua in Cienfuegos is analyzed.

The country does not have the technology for the extraction of mercury, leaving only glass as waste. There is only one vehicle that has this technology acquired by the electric company, but it is not enough to respond to the entire national territory.

The UIC Santiago de Cuba, in the implementation of the Environmental Management System has contemplated and registered the management of hazardous waste through the Management Plan for Hazardous Waste [12] complying with the provisions of Resolution 136/09 of the CITMA Regulation for the Management of Hazardous Waste, including its generation, handling, storage, final destination, means of protection, measures in case of accidents, training and contingency plan as well as the respective registers for 
its control, in the same way that the Inventories of environmental impacts and risks of other materials generated by other sectors [13] could have a spatial inventory of these wastes.

In each area where hazardous wastes are generated and managed, training is designed to ensure that all workers have knowledge of the proper handling of mercury and that they have full knowledge of the consequences for both health and the environment.

As a result of the research work is proposed queue: Any entity that manipulates mercury should have an area destined for an insurance and protection of this highly toxic product, keeping this polluting metal identified in the working environment and separated from all workers; use the means of protection properly, as long as this Soil Test is carried out; perform periodic medical check-ups, to mitigate the collateral damage that this chemical element produces and keep in mind the Security Requirements, for good handling and to avoid major problems.

\section{Conclusion}

a) Mercury is considered a high-risk heavy metal, so it is necessary to have knowledge of how it should be handled or the protections that people who are exposed to heavy metal must have, as well as its consequences for the health of each worker or loss fatal to life.

b) Workers who work with this product should be concerned and informed about the risks to which they are exposed in each job as well, thereby reducing the risks to which they are subject, gaining in health and quality of life, reducing workplace accidents.

\section{Conflict of interest statement and funding sources}

This work was done by specialists of the company and does not present any type of conflict of interests, with other specialists.

\section{Statement of authorship}

The authors have a responsibility for the conception and design of the study. The authors have approved the final article.

\section{Acknowledgments}

The authors thank the UIC for supporting the research so that workers with this research can acquire knowledge of the conditions that can cause the manipulation of mercury in the workplace. 


\section{References}

1. Alkapitani, M. (2017). The enrichment of new vocabularies in Sasak language because of gold mining spreading in Sekotong west Lombok. International Journal of Social Sciences and Humanities (IJSSH), 1(3), 182-193.

View in (Google Scholar)

2. Arcentales, G. A. T., Lucas, M. A. P., \& GuillÃ, R. (2017). Evaluation for the Reduction of NH3 Contamination Risks. International Journal of Life Sciences, 1(2), 10-17.

View in (Google Scholar)

3. Carvallo Suarez, B. (2003). Riesgos laborales del ejercicio profesional: una responsabilidad compartida. Actual. enferm, 6(3), 25-30.

View in (Google Scholar)

4. Castilla Cabanes, N. (2015). La Iluminación Artificial En Los Espacios Docentes (Doctoral dissertation). View in (Google Scholar)

5. Dababneh, A., Fouad, R. H., \& Majeed, A. J. H. (2018). Assessment of Occupational Safety and Health Performance Indicators for Jordan. Journal of Fundamental and Applied Sciences, 10(6S), 162-169.

View in (Google Scholar)

6. Gaioli, M., Amoedo, D., \& González, D. (2012). Impacto del mercurio sobre la salud humana y el ambiente. Archivos argentinos de pediatría, 110(3), 259-264.

View in (Google Scholar)

7. Gazzola, J. (2009). Uso de cinabrio en la pintura mural de Teotihuacán. Arqueología, (40), 57-70.

View in (Google Scholar)

8. Jain, P., Jain, A., Singhai, R., \& Jain, S. (2017). Effect of Biodegradation and Non Degradable Substances in Environment. International Journal of Life Sciences (IJLS), 1(1), 58-64.

View in (Google Scholar)

9. Kehrig, H. A., Baptista, G., Di Beneditto, A. P. M., Almeida, M. G., Rezende, C. E., Siciliano, S., ... \& Moreira, I. (2017). Biomagnificación de mercurio en la cadena trófica del Delfín Moteado del Atlántico (Stenella frontalis), usando el isótopo estable de nitrógeno como marcador ecológico. Revista de biología marina y oceanografía, 52(2), 233-244.

View in (Google Scholar)

10. Longo, D. L. (2012). Harrison: principios de medicina interna (18a. McGraw Hill Mexico. View in (Google Scholar)

11. María Rodríguez G., Alcides Mas R., Alain Destrade G. y Lázaro Valentín Rabelo P. (2008). Utilización de un Sistema de Información Geográfica para realizar los estudios de impacto ambiental en la Empresa Eléctrica Provincial de Santiago de Cuba. http://www.cubasolar.cu/Biblioteca/Ecosolar/Ecosolar24/HTML/articulo03.htm View in (Articles)

12. No, R. (2009). 136/2009 Reglamento para el manejo integral de desechos peligrosos. CITMA. Cuba. View in (Google Scholar)

13. Ramírez, A. V. (2008, March). Intoxicación ocupacional por mercurio. In Anales de la Facultad de Medicina (Vol. 69, No. 1, pp. 46-51). UNMSM. Facultad de Medicina.

View in (Google Scholar) 
14. Tejero Manzanares, J., Español Cano, S., Serrano García, J. J., \& Montes Tubío, F. D. P. (2011). Niveles de mercurio en ambiente y en fluidos biológicos: Caso de la metalurgia en Almadén, España (19862001). Salud de los Trabajadores, 19(2), 123-133.

View in (Google Scholar)

15. Tejero Manzanares, J., Español Cano, S., Serrano García, J. J., \& Montes Tubío, F. D. P. (2011). Niveles de mercurio en ambiente y en fluidos biológicos: Caso de la metalurgia en Almadén, España (19862001). Salud de los Trabajadores, 19(2), 123-133.

View in (Google Scholar)

16. Vera Carrasco, O. (2015). Uso de fármacos en el embarazo. Revista Médica La Paz, 21(2), 60-76. View in (Google Scholar) 


\section{Biography of Authors}

\begin{tabular}{||l|l||}
\hline Engineer in Mines, a specialist in quality has participated in different congresses, \\
publications, scientific seminars, MSC, a specialist in quality, currently dedicated \\
to environmental studies and deposition of hazardous waste in the soil. \\
Email: mariano@eniasc.co.cu
\end{tabular}

